\title{
Formação de Professores no IFMT: um Estudo Sobre o Histórico, Perfil do Egresso e a Organização Curricular de Licenciaturas em Ciências da Natureza - Habilitação em Biologia
}

\section{Teacher Training at the IFMT: a Study on the History, Profile of the Graduate and the Curricular Organization of Degrees in Natural Sciences - Biology}

\author{
Roseildo Nunes da Cruz ${ }^{\mathrm{a}}$, Leandro Carbo*b; Marcos Vinícius Ferreira Vilela ${ }^{\mathrm{c}}$
}

anstituto Federal de Mato Grosso, Campus São Vicente. MT, Brasil.

b'Instituto Federal de Mato Grosso, Programa de Pós-Graduação Stricto Sensu em Ensino. MT, Brasil.

'Universidade Federal de Goiás, Departamento de Educação em Ciências. GO, Brasil.

*E-mail: leandro.carbo@svc.ifmt.edu.br.

\begin{abstract}
Resumo
Nas últimas décadas foram propostas algumas iniciativas de reformulação dos programas de formação de professores de Ciências. Dentre elas, destacamos a implantação das Licenciaturas em Ciências da Natureza. Esses cursos têm como finalidade principal formar professores aptos a ensinar Ciências nos anos finais do ensino fundamental, sendo que alguns também ofertam habilitações para os campos disciplinares das Ciências da Natureza (Química, Física e Biologia). Em vista disso, o presente trabalho tem por objetivo conhecer o histórico, o perfil esperado do egresso e o modo de organização curricular de duas licenciaturas em Ciências da Natureza, com habilitação em Biologia, ofertadas pelo Instituto Federal de Mato Grosso (IFMT). Quanto à metodologia, utilizou-se a abordagem qualitativa, mediante um estudo exploratório e descritivo com base na análise documental dos projetos pedagógicos dos cursos supracitados. Por meio estudo realizado, foi possível perceber que essas licenciaturas almejam formar professores habilitados a lecionar os componentes curriculares de Ciências (ensino fundamental) e Biologia (ensino médio). Quanto aos objetivos de formação, depreende-se que eles se comprometem em ofertar uma formação docente que contribua com a ressignificação das práticas pedagógicas no ensino de Ciências da Natureza. No que tange à organização curricular, as licenciaturas se organizam em duas etapas: na primeira metade do curso, são ofertadas disciplinas voltadas à formação do professor de Ciências e, na segunda metade, disciplinas voltadas à formação de professores de Biologia. Todavia, entendemos que essa divisão do currículo possa se tornar um empecilho à oferta de uma formação interdisciplinar.
\end{abstract}

Palavras-chave: Formação Docente. Professores de Biologia. Ensino de Ciências da Natureza. Institutos Federais.

\begin{abstract}
In recent decades, some initiatives have been proposed for the reformulation of science teacher training programs. Among them, we highlight the implementation of Degrees in Nature Sciences. The main purpose of these courses is to train teachers able to teach Science in the final years of elementary school, and some also offer qualifications for the disciplinary fields of Natural Sciences (Chemistry, Physics and Biology). In view of this, the present work aims to know the history, the expected profile of the graduate and the way of curricular organization of two degrees in Natural Sciences, with specialization in Biology, offered by the Federal Institute of Mato Grosso (IFMT). As for the methodology, a qualitative approach was used, through an exploratory and descriptive study based on documental analysis of the pedagogical projects of the aforementioned courses. Through a study carried out, it was possible to see that these degrees aim to train teachers qualified to teach the curricular components of Science (primary education) and Biology (high school). As for the training objectives, it appears that they are committed to offering teacher training that contributes to the redefinition of pedagogical practices in the teaching of Natural Sciences. Regarding the curricular organization, the degrees are organized in two stages: in the first half of the course, subjects aimed at the formation of Science teachers are offered and, in the second half, subjects aimed at the formation of Biology teachers. However, we understand that this division of the curriculum can become an obstacle to the offer of an interdisciplinary training.
\end{abstract}

Keywords: Teacher Education. Biology Teachers. Teaching of Natural Sciences. Federal Institutes.

\section{Introdução}

A percepção sobre a importância da educação científica no contexto educacional brasileiro é relativamente nova. Essa constatação é comprovada pelo tempo necessário que foi disposto para que as disciplinas científicas passassem a ter um espaço no currículo escolar e por não avançarmos no modo como se concebe e se ensina os conhecimentos científicos. Ainda em muitos casos, a forma de se ensinar um conteúdo é centrada em um modelo conteudista, baseada na apresentação de conceitos estanques, enquanto a nossa concepção de ciência ainda acompanha os pensamentos consolidados no século XVII.

$\mathrm{Na}$ busca por compreender e encontrar soluções para essa problemática, diversos pesquisadores têm se dedicado a realizar investigações, visando discutir os problemas e encontrar soluções em prol da melhoria da educação científica. Estudiosos como Cachapuz et al. (2005) consideram a renovação do ensino de Ciências não apenas uma ressignificação da abordagem didático-metodológica das aulas, mas também uma mudança de postura epistemológica por parte dos professores.

Nessa perspectiva, não há como falar da melhoria 
do ensino de Ciências sem tratar da formação inicial dos professores. As novas demandas da sociedade e as concepções atuais de mundo e de ciência têm feito com que o papel da escola e do professor seja continuamente questionado. Nessa nova configuração escolar, o ensino de Ciências passa a ter a atribuição de conduzir os estudantes a compreender o mundo e a interpretar os fenômenos com os quais se depara no dia a dia (PIERSON; NEVES, 2011).

A história da formação de professores de Ciências e Biologia no Brasil teve início na década de 1930, quando foi criado o primeiro curso que formava profissionais na área de Ciências e Biologia, denominado História Natural. No início, como esse curso tinha por finalidade formar bacharéis, a visão dele era mais contemplativa da natureza, sem intervir sobre ela, mas os alunos recebiam uma sólida formação, especialmente em Biologia, Zoologia, Botânica e Geologia. Com a extinção do mesmo, por volta de 1963, houve desdobramento em dois novos cursos distintos, a saber, Geologia e Ciências Biológicas (TOMITA, 1990)

No ano de 1967, o curso de Ciências Biológicas passou a ser ofertado, permitindo a concessão de dois graus acadêmicos: licenciatura (formação de professores de Biologia para atuar no $2^{\circ}$ grau) e bacharelado (modalidade médica). A partir da promulgação da nova constituição em 1967, ocorreu a ampliação da gratuidade e obrigatoriedade do ensino em oito anos, que levou à necessidade da elaboração de uma nova Lei de Diretrizes e Bases da Educação, norma essa que viria a ser publicada no ano de 1971 (ASSIS, 2012). A ampliação do acesso à educação básica gratuita promoveu a urgência de formar mais professores para atender a essa demanda.

Uma das medidas tomadas pelo governo militar foi a criação das licenciaturas curtas, regulamentadas pela Resolução $\mathrm{CFE}^{1}$ n. ${ }^{\circ}$ 30/1974. Essa licenciatura curta em Ciências, com duração de dois anos e 1.800 horas, habilitava o professor para lecionar a disciplina de Ciências no $1^{\circ} \mathrm{Grau}$ (atual ensino fundamental). Caso o professor quisesse lecionar no $2^{\circ}$ grau (atual ensino médio), deveria cursar habilitação específica em um dos campos disciplinares das Ciências da Natureza (Química, Física, Biologia e Matemática).

Com a promulgação da LDB/1996² (BRASIL, 1996), as licenciaturas curtas foram extintas, ficando a formação inicial docente para a educação básica, a ser realizada em cursos de licenciatura plena. A partir do ano de 2002, foram instituídas as Diretrizes Curriculares Nacionais (DCNs) para a formação de professores. Atualmente, está em vigor a Resolução $\mathrm{CNE}^{3}$ n. ${ }^{\circ}$ 2, de 20 de dezembro de 2019, que define as Diretrizes Curriculares Nacionais para a formação inicial de professores para a educação básica e institui a Base Nacional Comum para a formação inicial de professores da educação básica (BNCFormação) (BRASIL, 2019).
No entanto, as constantes mudanças impostas aos cursos de licenciatura não foram capazes de ressignificar a formação inicial docente. Atualmente, esses cursos não têm conseguido formar professores que estejam aptos a lidar com esses novos desafios da escola e da educação científica. A maioria dos cursos que formam professores de Ciências e Biologia são estruturados com base em uma lógica curricular fragmentada, na qual os conhecimentos científicos são ensinados de forma individualizada e a "conta-gotas". Além disso, os licenciandos não são conduzidos a compreender as teorias bem como os conceitos científicos e biológicos dentro de um contexto histórico, e sujeito a influências externas.

Com isso, esse novo professor, ao chegar à escola, tende a reproduzir, na sua prática docente, as estratégias de ensino e a concepção de ciência na qual foi formado. Ele também não será capaz de compreender que a lógica do conhecimento científico não pode ser reproduzida fielmente no contexto escolar, devendo ser recontextualizada a partir de interesses sociais mais amplos (LOPES; MACEDO, 2011).

Nessa perspectiva, entendemos que um dos maiores desafios para o ensino de Ciências e Biologia seja aproximar as bases epistemológicas desse conhecimento aos objetivos do ensino das disciplinas científicas na escola. No que se refere à história e à epistemologia da Biologia, estas são relativamente novas, surgindo apenas no decorrer do século XX. Antes disso, a descrição e a compreensão dos fenômenos biológicos eram realizadas com base nas leis e teorias das Ciências Exatas.

Na perspectiva de buscar uma ressignificação da formação docente, ao longo da primeira década do século XXI, começaram a ser implementadas em diversas instituições, as Licenciaturas em Ciências da Natureza (LCNs). Tratase de uma nova proposta de formação de professores que, fundamentada na interdisciplinaridade, busca a superação de um ensino de ciências fragmentado e desconectado da realidade. Em tese, são cursos que se propõem a formar professores para assumirem as disciplinas de ciências nos anos finais do Ensino Fundamental (EF). Todavia, há também LCNs que ofertam habilitações para as disciplinas de Biologia, Química ou Física, ofertadas no Ensino Médio (EM).

Dentre as instituições ofertantes dessas licenciaturas destacamos os Institutos Federais (IFs). Essas instituições foram criadas por advento da Lei n. ${ }^{\circ} 11.892$, de 29/12/2008, que provocou transformação e/ou integração das instituições que formavam a Rede Federal de Educação Profissional e Tecnológica. A legislação supracidada atribuiu os IFs diversas finalidades, dentre elas ofertar programas de formação de professores, em especial para as áreas de Ciências e Matemática. Ainda de acordo com a referida lei, em seu art. $8^{\circ}$, os IFs devem garantir o mínimo de $20 \%$ de suas vagas ofertadas para atender tal finalidade (BRASIL, 2008). 
Nesse cenário, o Instituto Federal de Educação, Ciência e Tecnologia de Mato Grosso (IFMT) foi criado a partir da integração do Centro Federal de Educação Tecnológica de Mato Grosso, do Centro Federal de Educação Tecnológica de Cuiabá e da Escola Agrotécnica Federal de Cáceres. Trata-se de uma instituição de educação superior, básica e profissional, pluricurricular e multicampi, especializada na oferta de educação profissional e tecnológica nas diferentes modalidades de ensino (IFMT, 2019b). Atualmente, o IFMT oferta 16 cursos de licenciatura nas áreas de Ciências da Natureza, Matemática e Pedagogia, distribuídos em dez campi, situados em nove cidades do estado do Mato Grosso.

Tendo em vista o que foi exposto, esta investigação tem por objetivo conhecer o histórico, o perfil do egresso e o modo de organização curricular de duas licenciaturas em Ciências da Natureza, com habilitação em Biologia, ofertadas pelo Centro de Referência de Jaciara/MT e Campus Avançado de Guarantã do Norte/MT, unidades acadêmicas vinculadas ao IFMT.

\section{Material e Métodos}

O presente trabalho caracteriza-se como uma investigação de abordagem qualitativa, com cunho exploratório e descritivo. De acordo com Sampieri, Collado e Lucio (2013, p.16), a pesquisa qualitativa "dá profundidade aos dados, além da dispersão, riqueza interpretativa, contextualização do ambiente, detalhes e experiências únicas". Também oferece um ponto de vista "recente, natural e holístico dos fenômenos, assim como flexibilidade."

Quanto ao procedimento, optou-se pela pesquisa documental como fonte de pesquisa. A escolha pelos procedimentos técnicos e respectivos instrumentos de produção de dados se deu por ser adequada à abordagem e aos objetivos da investigação, além de fornecer dados significativos para permitir uma resposta adequada ao problema de pesquisa.

Quando pensamos em utilizar a pesquisa documental, deparamo-nos com a oportunidade de encontrar uma fonte rica em dados qualitativos. Nesse segmento, podemos considerar, como fontes documentais, as cartas, a reportagem, o jornal, os diários, os documentos institucionais etc. (SAMPIERI; COLLADO; LUCIO, 2013). Para a realização da pesquisa ora apresentada, foram analisados os PPCs de dois cursos de Licenciatura de Ciências da Natureza com habilitação em Biologia, ofertados em dois Campi do IFMT: Campus Avançado de Guarantã do Norte e Campus São Vicente - Centro de Referência de Jaciara, que passaremos a denominar respectivamente de LCN/Bio/GTA e LCN/ $\mathrm{Bio} / \mathrm{SVC}$. Importante dizer que as duas LCNs investigadas formam professores para as disciplinas de Ciências para o EF e Biologia para o EM.

Com os PPCs em mãos, de forma a atender ao objetivo da pesquisa, esses documentos foram analisados considerando as seguintes categorias: 1) IFMT: seu histórico e papel na formação de professores; 2) LCN/Bio/SVC: Histórico, perfil esperado do egresso e organização curricular e; 3) LCN/Bio/ GTA: Histórico, perfil esperado do egresso e organização curricular.

\section{Resultados e Discussão}

Preliminarmente, é importante salientar que a exploração dos documentos dos dois cursos pesquisados (PPCs), foi realizada inicialmente de forma semelhante à fase da leitura flutuante. Esse processo foi importante para que pudéssemos nos familiarizar com as seções e conteúdos existentes nos documentos de modo a perceber se as informações fundamentais para atender aos objetivos da pesquisa estariam neles presentes. Em seguida, foram extraídos fragmentos dos documentos cuja seleção foi baseada na relevância de sua contribuição para atender as categorias de análise estabelecidas.

\subsection{IFMT: seu histórico e papel na formação de professores}

A centenária Rede Federal de Educação Profissional e Tecnológica iniciou-se em 1909, quando Nilo Peçanha, Presidente da República naquele período, em 23 de setembro, por meio do Decreto n. ${ }^{\circ} 7.566$, criou 19 escolas de aprendizes e artífices, todas elas subordinadas ao Ministério dos Negócios da Agricultura, Indústria e Comércio. O ponto de partida da educação profissional no estado de Mato Grosso ocorreu em 1910, com a criação da Escola de Aprendizes Artífices de Mato Grosso (atual Instituto Federal de Mato Grosso IFMT). Essa instituição de educação profissional foi criada com o objetivo de munir o aluno de uma arte que o habilitasse a exercer uma profissão e a se manter como artífice (BRASIL, 2009; KUNZE, 2009; MARQUES; INÁCIO FILHO, 2017).

Em 1930, com Getúlio Vargas no comando do país, foi estabelecido um novo rumo à economia brasileira, tendo como foco a atividade industrial. Isso fez com que fosse gerada uma intensa expansão, sendo necessário, então, aumentar a quantidade de mão de obra para atuar no setor e, por consequência, preparar novos trabalhadores. Assim, em 1937, foi promulgada a nova constituição brasileira, que trouxe, pela primeira vez, o ensino técnico profissional e industrial, por meio da Lei n. ${ }^{\circ}$ 378, de 1937, a qual transformou as Escolas de Aprendizes e Artífices em Liceus Industriais e estabeleceu o ensino profissional em todos os ramos e graus (STERING, 2018).

Durante o governo Vargas, foi fortalecido o papel das escolas agrícolas, visando à efetivação do projeto agrícola brasileiro. No intento de promover a capacitação dos profissionais que viriam a contribuir com o desenvolvimento agrícola do estado de Mato Grosso, foi criado, em 1943, o “Aprendizado Agrícola Gustavo Dutra” (atual IFMT Campus São Vicente).

Essa unidade de ensino passou a ser referência de formação agrícola no estado de Mato Grosso, propiciando 
maior inclusão social e crescimento econômico local, além de fornecer mão de obra qualificada às empresas incipientes no estado (MARQUES; INÁCIO FILHO, 2017).

No ano de 1959, durante o governo de Juscelino Kubitschek, as escolas técnicas e industriais foram transformadas em autarquias, passando à denominação de Escolas Técnicas Federais (ETFs). Entre as décadas de 1960 a 1980, o Brasil passa a ser governado por uma ditadura militar. Nesse período, houve uma profunda transformação da educação brasileira, sendo a educação profissional considerada como uma das molas propulsoras para o desenvolvimento industrial (KUNZE, 2009).

Um marco importante nessa transformação ocorreu em 1978, ano em que foram criados os primeiros Centros Federais de Educação Tecnológica (CEFETs), que, por sua vez, surgiram a partir da transformação das Escolas Técnicas Federais do Paraná, Minas Gerais e Rio de Janeiro. Desta forma, os primeiros CEFETs foram implantados em 1978, nos estados de Minas Gerais, Rio de Janeiro e Paraná. Na sequência, foram implantados nos estados do Maranhão (1989) e Bahia (1993) (NASCIMENTO, 2012; ARAÚJO, 2016). Essas foram as primeiras instituições de educação profissional a terem a incumbência de ofertar cursos superiores (BRASIL, 2009).

De acordo com Araújo (2016, p.30), os CEFETs seriam responsáveis pela oferta de cursos superiores, "expandindo e diversificando sua atuação, mas sem sair da área de formação profissional, seguindo a finalidade de criação desses estabelecimentos de ensino, a de formar pessoas para ofertar mão de obra especializada". Os primeiros CEFETs foram criados na perspectiva de que as instituições de educação profissional também ofertassem cursos superiores, enquanto aqueles criados entre os anos de 1990 e 2000, apesar de manterem a oferta da educação superior, tiveram por finalidade se consolidar como instituições especializadas na oferta de educação profissional e tecnológica (FLACH, 2014).

Assim sendo, fica evidente que os CEFETs, criados no final da década de 1990, buscavam atender a demandas diferentes daqueles iniciados duas décadas antes. Dentre as formações ofertadas nessas instituições, destacamos a retomada dos cursos de ensino médio integrado e da oferta de licenciaturas e programas especiais de formação pedagógica, com ênfase nas áreas científica e tecnológica.

Além de cursos de graduação em engenharia industrial e tecnólogos, essas instituições de educação profissional foram incumbidas de ofertar cursos de licenciatura plena e de curta duração. Naquele momento, os cursos de licenciatura ofertados pelos CEFETs tinham por objetivo suprir o déficit de professores da própria rede de educação profissional.

A criação dos CEFETs em outras regiões do Brasil veio a ocorrer apenas no final dos anos 1990 e início dos anos 2000. Nesse período, diversas Escolas Técnicas Federais já existentes foram transformadas em CEFETs. Todavia, o espaço de tempo existente entre os processos de "cefetização", iniciados nas décadas de 1970 e 1990, respectivamente, promoveu diferenças significativas entre os objetivos e as finalidades dessas instituições.

Nos anos 2000, a autonomia acadêmico-administrativa dos CEFETs foi ampliada, fazendo com que pudessem implantar novos cursos de formação de professores sem a necessidade de autorização prévia do Ministério da Educação (VIANNA, 2005; FLACH, 2014).

Apesar da ampliação da autonomia dos CEFETs, estes a tinham num patamar inferior daqueles criados na década de 1970. Essa distorção foi gerada pela vinculação dessas instituições a diferentes Secretarias do MEC. Enquanto os CEFETs implantados antes de 1994 estavam sob a supervisão da Secretaria de Educação Superior, aqueles que foram criados após esse período estavam sob a responsabilidade da Secretaria de Educação Média e Tecnológica. Essa distinção no processo de administração e supervisão dos CEFETs fez com que as licenciaturas por eles ofertadas apresentassem condições díspares de oferta (VIANNA, 2005).

De acordo com Pansardi (2013), a oferta de cursos de licenciatura pelos CEFETs vem na esteira de reformas educacionais promovidas durante o governo Fernando Henrique Cardoso (FHC). Essas mudanças tiveram uma grande influência de concepções difundidas pelo Banco Mundial. É importante lembrar que, durante o governo FHC, a expansão da educação profissional e tecnológica no Brasil ficou bastante comprometida.

A retomada dessa expansão somente ocorreu no governo Lula, no qual, a partir do ano de 2005, foi lançada a primeira fase do Plano de Expansão da Rede Federal de Educação Profissional e Tecnológica (RFEPT). A segunda fase do plano foi implantada no ano de 2007, a partir da Chamada Pública MEC/SETEC n. ${ }^{\circ}$ 02/2007, em que as instituições de educação profissional e tecnológica foram convidadas a aderir a uma nova configuração da RFEPT, que, mais adiante, em 2008, resultou na criação dos Institutos Federais (IFs) (BRASIL, 2009, FLACH, 2014).

Dentre os objetivos dos IFs destacamos a missão dessas instituições de ofertarem cursos de formação de professores para a educação básica, em especial para as áreas de Ciências da Natureza e Biologia. Em tese, essa função atribuída aos IFs se dá na perspectiva de reduzir o déficit histórico de professores para essas áreas do conhecimento.

Todavia, de acordo com Flach (2014, p.87),

No que se refere à formação de professores nas instituições que deram origem aos IFs, percebe-se que estas instituições, de modo geral não possuem experiências consolidadas na oferta de cursos de licenciatura, ou seja, na formação de docentes para atuação na Educação Básica. É uma tradição que ainda deverá ser construída e esta tarefa certamente não será simples, tendo em vista os diversos desafios que se impõem para esta modalidade de ensino nos Institutos Federais.

No que tange ao IFMT, este possui atualmente 14 campi no estado de Mato Grosso, sendo eles: Alta Floresta, Barra do Garças, Cáceres, Campo Novo do Parecis, Confresa, 
Cuiabá - Octayde Jorge da Silva, Cuiabá - Bela Vista, Juína, Pontes e Lacerda, Primavera do Leste, São Vicente, Sorriso, Rondonópolis e Várzea Grande. O Instituto conta ainda com unidades descentralizadas em outros oito municípios do estado, organizados na forma de Campus Avançados, nos municípios de Tangará da Serra, Diamantino, Lucas do Rio Verde, Sinop e Guarantã Norte, e de Centros de Referência, em Campo Verde, Jaciara e Paranaíta (IFMT, 2019).

Dentre as unidades acadêmicas acima descritas, 10 delas ofertam 16 cursos de licenciatura, sendo que a maioria desses se dedicam à formar professores para a área de Ciências da Natureza e Matemática. O IFMT oferta ainda dois cursos de mestrado na área de ensino: Mestrado Acadêmico em Ensino em ampla associação com a Universidade de Cuiabá (UNIC) e o Mestrado Profissional em Educação Profissional e Tecnológica (PROFEPT), em rede. Diante do cenário apresentado, é possível supor que o IFMT tem se concentrado na oferta de cursos de licenciatura em áreas que coadunam com a sua missão institucional. Todavia, ainda é importante salientar que a sua contribuição em caráter qualitativo para a formação de professores de Ciências não depende apenas da oferta de cursos e vagas nas áreas supracitadas. É importante que a instituição se debruce na elaboração e na implementação de políticas institucionais que contribuíam com a constituição de sua identidade como institucionalidade formadora de professores.

\subsection{LCN/Bio/SVC: Histórico, perfil esperado do egresso e organização curricular}

A LCN/Bio/SVC, iniciou o seu funcionamento no ano de 2017, ofertando um total de 35 vagas, com ingresso anual. O curso é oferecido pelo Centro de Referência de Jaciara (CRJac), unidade acadêmica descentralizada, vinculada ao IFMT - Campus São Vicente. A LCN/Bio/SVC tem duração de 4 anos ( 8 semestres) e uma carga horária total de 3.226 horas.

A motivação para criação do curso emergiu da percepção de que havia a necessidade de ofertar uma habilitação específica, visto que, desde o ano de 2010, o CRJac já vinha ofertando a licenciatura em Ciências da Natureza (LCN). No entanto, esse curso habilitava os seus licenciados para atuarem apenas nas séries finais do ensino fundamental.

A opção pela habilitação em Biologia veio da compatibilidade entre o corpo docente, necessário à sua oferta e ao grupo de professores que já lecionavam no Campus São Vicente.

A LCN/Bio/SVC, de acordo com o seu Projeto Pedagógico de Curso (PPC):

[...] tem como objetivo formar professores capazes de articular os saberes de forma interdisciplinar, contemplando uma formação abrangente e consistente sobre as abordagens científicas, o conhecimento pedagógico e as novas demandas sociais apresentadas para o ensino de Ciências Naturais e Biológicas. (IFMT, 2019a, p. 23).
A partir das contribuições dos estudos de Bierhalz, Araujo e Lima (2013) e Flach (2014) podemos inferir que o aproveitamento da infraestrutura e do corpo docente existente têm sido os principais critérios considerados para a implementação dos cursos de licenciatura nos IFs. Tratase de uma medida de contenção de despesas, visto que a maioria dessas instituições possuem infraestrutura e corpo docente com formação, sobretudo, nas áreas de Ciências da Natureza e Matemática. Nessa medida, caberá aos professores dessas licenciaturas, após a sua implementação, lutarem por condições adequadas de trabalho, formação continuada e de infraestrutura em prol da oferta de uma formação docente que realmente contribua com a melhoria da educação básica. Caso contrário, estaremos falando apenas em um aumento quantitativo no número de professores formados nessas áreas.

Schnetzler (2002) tem questionado sobre um novo significado na formação desse docente, devido às transformações ocorridas na sociedade e aos avanços tecnológicos. Por esse motivo, exige-se uma ressignificação dessa formação, sendo possível perceber a importância de aproximar os conhecimentos de forma interdisciplinar, possibilitando uma conexão direta com o mundo real. Nessa medida, uma das características intrínsecas aos IFs que podem contribuir com essa ressignificação da formação docente, diz respeito à verticalização do ensino e capilaridade do ensino promovida por essas instituições.

Os IFs têm autonomia para a oferta de cursos em diversos níveis de ensino, que vão da educação básica à pós-graduação stricto sensu (verticalização do ensino). Essa característica dá aos professores a possibilidade de estabelecerem um contato permanente com a educação básica, visto que podem atuar nesses dois níveis de ensino. Nessa perspectiva, desde que assegurada uma adequada condição de formação continuada e de trabalho ao docente, existe a possibilidade de que os professores possam oportunizar aos licenciandos subsídios mais robustos, visando uma análise crítica da realidade da educação básica. Entendemos que tal possibilidade seria mais favorável para ocorrer nos IFs do que nos tradicionais programas de formação de professores ofertados pelas Universidades. Ademais, os IFs possuem unidades acadêmicas fixadas em municípios de menor porte, locais esses que as Universidades não conseguiram atender (capilaridade do ensino).

As condições de verticalização e capilaridade, com base na análise documental, se fazem presentes no Centro de referência de Jaciara CRJac, unidade acadêmica ofertante da LCN/Bio/SVC. Nesta mesma unidade é ofertado um curso de Ensino Médio Integrado (EMI) em Meio Ambiente. Ademais, muitos dos professores que atuam na LCN/Bio/IFMT também atuam no EMI. Ademais, o CRJac está situado em uma região denominada de "Vale do São Lourenço", cuja população está estimada em mais de 50.000 mil habitantes. Trata-se de uma localidade que não conta com outra instituição de educação 
superior pública e gratuita. Dessa forma, aliando-se às condições de verticalização e capilaridade a uma adequada política institucional de formação de professores, existe aí uma promissora possibilidade de melhoria da formação docente.

Quanto ao perfil do egresso, espera-se que os licenciados nesse curso estejam aptos a promover a aprendizagem do educando, considerando o saber científico. O egresso deverá saber relacionar as quatro áreas: Biologia, Química, Física e Matemática, de forma interdisciplinar, de modo a incentivar o estudo investigativo. Ao final de sua formação, almeja-se que os licenciados tenham obtido "uma formação abrangente e consistente sobre as abordagens científicas e o conhecimento pedagógico na área de Ciências do Ensino Fundamental e de Biologia para o Ensino Médio" (IFMT, 2019a, p. 38).

Entendemos que tal formação, fundamentada em uma visão de Ciência integrada, possa contribuir para a superação de um modo fragmentado e linear de conceber os processos e fenômenos científicos e biológicos. Tal condição poderia proporcionar aos licenciandos a condição de realizarem análises, reflexões e intervenções mais elaboradas sobre a realidade que os cerca. Nesta mesma linha, Carvalho e GilPérez (2011) apontam a necessidade formativa do professor de Ciências, dando destaque à ruptura que esse profissional deve ter diante das visões simplistas e sobre o que seja ensinar Ciências.

No que tange à organização curricular, o PPC da LCN/ Bio/SVC descreve que o currículo do curso foi construído de forma coletiva e com foco no acadêmico. Para estabelecer o equilíbrio entre os diferentes conhecimentos que envolvem a formação dos professores de Ciências e Biologia, durante a estruturação do currículo, foi favorecida a participação de professores de diferentes áreas do conhecimento. Além disso, buscou-se estruturar as disciplinas a partir de temas, oportunizando a interdisciplinaridade e a contextualização intra e entre conteúdos/disciplinas ao longo do curso.

A matriz do curso está organizada em dois eixos: Ciências da Natureza e Ciências Biológicas. O eixo Ciências da Natureza agrupa um conjunto de disciplinas que abordam conteúdos de Química, Física, Noções de Biologia e elementos de Geologia. Essas disciplinas são ofertadas nos quatro primeiros semestres do curso. A partir dos conteúdos ofertados nessa primeira etapa do currículo, almeja-se ofertar aos alunos um conjunto de conhecimentos de modo a preparálos para lecionar a disciplina de Ciências nas séries finais do ensino fundamental. A seleção dos conteúdos abordados nessas disciplinas tem como referência os Parâmetros Curriculares Nacionais (PCNs) dos anos finais do EF.

Quanto ao eixo Biologia, com disciplinas na segunda metade do curso, são ofertados os conhecimentos específicos e pedagógicos necessários à formação do professor de Biologia. A seleção dos conteúdos específicos e pedagógicos bem como a definição da carga horária das atividades de formação profissional têm como referência as Diretrizes Curriculares Nacionais (DCNs), para os cursos de Ciências Biológicas (bacharelado e licenciatura) (Resolução CNE n. ${ }^{\circ}$ 7/2002), e as DCNs, para os cursos de formação inicial em nível superior (cursos de licenciatura, cursos de formação pedagógica para graduados e cursos de segunda licenciatura) e para a formação continuada (Resolução CNE n. ${ }^{\circ}$ 02/2015).

A utilização dos PCNs como referencial curricular para a formação de professores para a disciplina de Ciências no EF se deve, fundamentalmente, à ausência de diretrizes e/ou referenciais curriculares próprios para os cursos que formam professores para esse nível de ensino. Historicamente, a atribuição de lecionar a disciplina de Ciências tem ficado a cargo do licenciado em Ciências Biológicas. Todavia, Magalhães-Júnior \& Pietrocola (2010) alertam que os cursos tradicionais de licenciatura em Ciências Biológicas não são os mais adequados para formar professores de Ciências para o EF, tendo em vista os seus currículos altamente "biologizados".

No que diz respeito à $\mathrm{LCN} / \mathrm{Bio} / \mathrm{SVC}$, dois referenciais foram balizadores da estruturação do seu currículo: os PCNs e as DCNs para os cursos de Ciências Biológicas. Nessa perspectiva, a matriz curricular foi organizada em dois grandes grupos de componentes curriculares, um grupo composto por componentes curriculares que tornará o licenciando apto a ensinar Ciências no EF e outro grupo composto por componentes curriculares voltados à formação do professor de Biologia para o EM. Nesse sentido, é importante dizer que para além de se pensar em quais conhecimentos e/ ou disciplinas são necessárias para se formar um professor de Ciências e Biologia, deve-se considerar de que modo os licenciandos construirão suas concepções de Ciência a partir da formação que receberão. Se o objetivo é formar um professor de Ciências da Natureza capaz de romper com o ensino linear e fragmentado dos conteúdos científicos, a organização curricular proposta para o curso que irá formá-lo também deve ser concebida com esse mesmo objetivo.

Quanto à formação interdisciplinar almejada pela LCN/ Bio/SVC, Cavalcanti (2014) indica que as tendências atuais para a formação docente vêm apontando para a essencialidade de se conceber novos modelos de licenciatura, que sejam fundamentados no paradigma interdisciplinar. Essa nova concepção formativa tem por objetivo superar a atual formação disciplinar, que é baseada na abordagem de conhecimentos estanques e fragmentados. Por conseguinte, a partir dessa ressignificação da formação do professor, esperase que o docente tenha condições de discutir e analisar temas sociais complexos em sala de aula, conduzindo seus alunos a um aprendizado voltado à cidadania.

Contudo, a implantação do novo modelo de interdisciplinaridade na formação docente e no ensino de Ciências enfrenta muitos entraves. Podemos salientar que o ato de interdisciplinaridade requer do professor uma maior aplicação de tempo, indo contra o modelo tradicional de ensino, forçando-o a sair da zona de conforto (FAZENDA, 2011). Nessa perspectiva, entendemos que a oferta de uma formação interdisciplinar pela LCN/Bio/SVC dependerá, 
dentre vários fatores, de uma organização institucional e de condições de trabalho que favoreçam a interdisciplinaridade e de que os professores do curso estejam cientes e motivados para superar os desafios que irão enfrentar.

\subsection{LCN/Bio/GTA: Histórico, perfil esperado do egresso e organização curricular}

A LCN/Bio/GTA iniciou o seu funcionamento no ano de 2017 com a oferta de 35 vagas por meio de ingresso anual. A licenciatura é oferecida pelo Campus Avançado de Guarantã do Norte tendo uma duração de 4 anos ( 8 semestres) e carga horária total de 3.208 horas.

A LCN/Bio/GTA tem por objetivo "formar professores para a educação básica, na área de Ciências da Natureza e Suas Tecnologias", tornando-os aptos a lecionar as disciplinas de Ciências e Biologia no EF e EM, respectivamente. Além disso, essa licenciatura almeja "promover discussões que busquem a melhoria da educação, oferecendo ferramentas e propostas de ensino que contribuam para a melhoria da qualidade da educação da região". Por meio da formação ofertada, "o licenciado nesse curso deverá ser capaz de apreender o contexto social e escolar em que estiver inserido, proporcionando aos seus alunos a compreensão da natureza e de seus fenômenos a partir de uma abordagem interdisciplinar" (IFMT, 2017, p. 22).

Conforme evidenciou o PPC do curso, a LCN/Bio/GTA foi concebida e implementada com o objetivo de formar professores de Ciências e Biologia para atuarem na região de abrangência do Campus Avançado de Guarantã do Norte. Trata-se de uma região sediada na porção norte do estado de Mato Grosso que não contava, até o momento de implantação do campus, de uma instituição pública e gratuita de educação superior.Além da licenciatura, essa unidade acadêmica também oferta o curso de EMI em Agropecuária e os cursos superiores em Zootecnia (bacharelado) e Agroindústria (Tecnólogo). Nessa perspectiva, entendemos que a implantação do referido campus e da LCN/Bio/GTA pelo IFMT coaduna com os objetivos de verticalização e capilaridade almejados para os IFs.

Ao final de sua formação, espera-se que o egresso da LCN/Bio/GTA esteja apto a "promover a aprendizagem de seus alunos, tendo como base o conhecimento científico" (IFMT, 2017, p. 33). Além disso, precisará ser capaz de relacionar interdisciplinarmente os conhecimentos oriundos de quatro campos disciplinares: Biologia, Física, Química e Matemática.

Segundo o PPC, existe a possibilidade de que o egresso desse curso possa atuar como biólogo em projetos, pesquisas, perícias, análises, fiscalização, emissão de laudos, dentre outras atividades descritas na Resolução do Conselho Federal de Biologia (CFBio) n. ${ }^{\circ}$ 227/2010. No entanto, essa atuação técnica dependerá de uma complementação na sua formação.

$\mathrm{O}$ trabalho interdisciplinar também aparece como uma das aptidões almejadas para os egressos da LCN/
Bio/GTA. Todavia, não está evidente no PPC qual seria a concepção de interdisciplinaridade que daria sustentação para essa formação. Ademais, o texto do documento demonstra uma maior preocupação em conceder um leque de possibilidades de atuação profissional de modo a viabilizar a inserção desses profissionais no mercado de trabalho. Entendemos que tais condições podem dificultar a superação da fragmentação do conhecimento científico por meio da interdisciplinaridade e impedir a construção de uma identidade docente adequada pelos licenciandos. Tal cenário pode promover na prática, a implementação de uma "licenciatura bacharelesca", ou seja, a graduação nominalmente é oferecida como um curso de licenciatura, mas o seu foco recai apenas nos conhecimentos específicos do bacharelado.

Quanto à sua organização curricular, o PPC da LCN/ Bio/GTA expõe que a construção do currículo do curso se deu a partir de um trabalho coletivo, visando garantir que os componentes curriculares e os conteúdos abordados no curso não fossem definidos de maneira isolada. O currículo do curso é organizado em duas etapas de formação, sendo que as disciplinas cursadas durante os quatro primeiros semestres do curso preparam o professor para lecionar Ciências no ensino fundamental, e os quatro últimos semestres são compostos por disciplinas que irão preparar o licenciando para lecionar Biologia no ensino médio.

A organização do currículo da LCN/Bio/GTA também se estrutura a partir de dois grandes grupos de componentes curriculares que são ofertados em diferentes etapas da formação. Nessa perspectiva, assim como ocorre com o PPC da LCN/Bio/SVC, essa divisão do currículo pode promover uma concepção nos estudantes que a natureza do conhecimento científico dos temas tratados na disciplina de Ciências é diferente daqueles temas tratados na disciplina de Biologia. Entendemos que tal concepção tende a reafirmar nos estudantes uma concepção de Ciência pautada no paradigma empírico-indutivista que, ao nosso ver, não coaduna com a pretensão da oferta de uma formação interdisciplinar.

A seleção dos conteúdos específicos e pedagógicos bem como a definição da carga horária das atividades de formação profissional têm como referência as Diretrizes Curriculares Nacionais (DCNs), para os cursos de Ciências Biológicas (bacharelado e licenciatura) (Resolução CNE n. ${ }^{\circ}$ 7/2002), e as DCNs, para os cursos de formação inicial em nível superior (cursos de licenciatura, cursos de formação pedagógica para graduados e cursos de segunda licenciatura) e para a formação continuada (Resolução CNE n. ${ }^{\circ}$ 02/2015).

Conforme mencionado anteriormente, o documento que balizou a definição dos componentes curriculares e os conteúdos específicos que compõem o currículo da LCN/ Bio/TGA foram as DCNs para os cursos de bacharelado e licenciatura em Ciências Biológicas. Em suma, entendemos que a opção por este documento se deve a ausência de diretrizes e/ou referenciais curriculares específicos para as licenciaturas em Ciências da Natureza. Todavia, é importante citar que tal 
contexto tende a reduzir a importância dos conteúdos e das abordagens teórico-metodológicas específicas para ensinar ciências no EF. Nessa perspectiva, os licenciados nesse curso poderão não ter acesso a conteúdos específicos e pedagógicos fundamentais para se lecionar a disciplina de Ciências nesse nível de ensino.

Contribuindo com esta discussão Martinez (2015) ressalta que as DCNs para os cursos de Ciências Biológicas trazem poucas contribuições para a formação dos professores de Biologia. Segundo a autora, como são diretrizes para cursos de bacharelado e licenciatura, as concepções de formação são generalistas, na perspectiva de formar profissionais que possam atuar em diferentes espaços profissionais. A falta de uma discussão mais profícua sobre as questões relacionadas à profissão docente expõe que as DCNs para os cursos de Ciências Biológicas priorizam uma formação que visa ao desempenho de atividades profissionais típicas do bacharel, ficando a atuação docente em segundo plano.

\section{Conclusão}

O IFMT enquanto nova institucionalidade de formação de professores no estado de Mato Grosso, considerando o que emerge dos documentos analisados, tem buscado cumprir a sua missão institucional de formar professores de Ciências da Natureza e Matemática para a educação básica. Neste ínterim, entendemos que as principais características institucionais que contribuem para o avanço da formação docente são as suas condições de capilaridade e verticalização do ensino.

As licenciaturas aqui investigadas almejam, em suma, formar professores de Ciências e Biologia que sejam capazes de promover uma ressignificação no modo de ensinar os conteúdos científicos. Nesse segmento, tendo como base o paradigma interdisciplinar, essas licenciaturas esperam que seus egressos sejam capazes de aliar os conhecimentos científicos ao cotidiano dos alunos, de modo que o conhecimento aprendido na escola encontre lugar e utilidade na sua formação enquanto cidadão.

Quanto ao perfil do egresso, ambas as licenciaturas objetivam formar professores que irão lecionar Ciências no ensino fundamental e Biologia no ensino médio. Apenas a LCN/Bio/GTA cita a possibilidade de que seus licenciados possam desenvolver atividades típicas de bacharéis em Biologia, no entanto, condicionam essa possibilidade a uma complementação da formação. Todavia, entendemos que tal concessão pode ser temerária, visto que o licenciando, ao longo deste curso, pode ter dificuldades em construir a sua identidade docente.

No que se refere à organização curricular, as duas licenciaturas organizam seus currículos de modo a separar a formação do professor de Ciências e do professor de Biologia. Assim, na primeira metade desses cursos ( $1^{\circ}$ a $4^{\circ}$ semestre), são ofertadas disciplinas voltadas à preparação do licenciando para atuar na disciplina de Ciências no ensino fundamental. Por sua vez, na metade final dos cursos ( $5^{\circ}$ a $8^{\circ}$ semestres), são ofertadas disciplinas que deverão preparar o licenciando para ensinar Biologia no ensino médio. Nessa perspectiva, entendemos que esse fracionamento do currículo não corrobora com o ideal de uma formação interdisciplinar invocado recorrentemente nos PPCs das licenciaturas. Consideramos também que em, alguns aspectos, o modo como os currículos desses cursos estão analisados se assemelham à organização curricular das "licenciaturas curtas" em Ciências implantadas na década de 1970.

Por fim, consideramos que para a consolidação do conhecimento sobre como efetivamente funcionam, se organizam e quais as contribuições das Licenciaturas em Ciências da Natureza - Habilitação em Biologia, é necessário um estudo mais aprofundado que considere fontes adicionais de dados. Nessa perspectiva, a entrevista com os gestores das unidades acadêmicas, com os professores e estudantes desses cursos poderiam trazer contribuições substanciais para esse objeto de estudo.

\section{Referências}

ARAÚJO, W.S. Das Escolas Técnicas Federais aos Institutos Federais: a licenciatura em Física no campus Goiânia do IFG. Goiania: Universidade Federal de Goiás, 2016.

ASSIS, R.M. A educação brasileira durante o período militar: a escolarização dos 7 aos 14 anos. Educ. Perspectiva, v.3, n.2, p.320-339, 2012. doi: https://doi.org/10.22294/eduper/ppge/ufv. v3i2.171.

BIERHALZ, D.C.K.; ARAÚJO, R.R.; LIMA, V.A. Licenciatura Interdisciplinar em Ciências da Natureza: análise do Projeto Pedagógico do Curso. In: SIMPÓSIO INTERNACIONAL SOBRE INTERDISCIPLINARIDADE NO ENSINO, NA PESQUISA E NA EXTENSÃO. Santa Catarina/SC. Anais... Santa Catarina/SC, 2013. Disponível em: <http://www.siiepe. ufsc.br/wp-content/uploads/2013/10/A-Bierhalz.pdf>.

BRASIL. Ministério da Educação. Lei de Diretrizes e bases da educação nacional. Lei no 9.394, de 20 de dezembro de 1996. Disponível em: http://www.planalto.gov.br/ccivil_03/leis/L9394. $\mathrm{htm}$. Acesso em: 10 maio 2020.

BRASIL. Resolução CNE/CES n 07, de 11 de março de 2002. Estabelece as Diretrizes Curriculares para os cursos de Ciências Biológicas. Brasília: MEC/CNE, 2002.

BRASIL. Lei n. 11892/2008. Institui a Rede Federal de Educação Profissional, Científica e Tecnológica, cria os Institutos Federais de Educação, Ciência e Tecnologia, e dá outras providênciasImprensa Nacional, 2008. Disponível em: http://www.porto.ifto.edu.br:8082/documentos/doc_oficiais/ Lei_11892.doc_INSTITUTOS_FEDERAIS.pdf. Acesso em: 11 abr. 2020 .

BRASIL. Linha do tempo: rede federal de educação profissional e tecnológica. Recife: Fundação Joaquim Nabuco, 2009.

BRASIL. Diretrizes Curriculares Nacionais para a Formação Inicial de Professores para a Educação Básica e Base Nacional Comum para a Formação Inicial de Professores da Educação Básica (BNC-Formação). 2019. Disponível em: https://www. cenpec.org.br/wp-content/uploads/2020/01/pcp022_19.pdf. Acesso em: 3 maio 2021.

CACHAPUZ, A. et al. A necessária renovação do ensino das Ciencias. São Paulo: Cortez, 2005. 
CARVALHO, A.M.P.; GIL-PÉREZ, D. Formação de professores de ciencias tendências e inovações. São Paulo: Cortez, 2011.

CAVALCANTI, A.D.S. Olhares epistemológicos e a pesquisa educacional na formação de professores de ciências. Educ. Pesq., v.40, n.4, p.983-998, 2014. doi: http://dx.doi.org/10.1590/s151797022014121459 .

FAZENDA, I.C.A. Integração e interdisciplinaridade no ensino brasileiro: efetividade ou Ideologia. São Paulo: Edições Loyola, 2011.

FLACH, Â. Formação de professores nos institutos federais: estudo sobre a implantação de um curso de licenciatura em um contexto de transição institucional. Rio dos Sinos: Universidade do Vale do Rio dos Sinos, 2014.

IFMT. Instituto Federal de Educação, Ciência e Tecnologia. Projeto Pedagógico do Curso de Licenciatura em Ciências da Natureza com Habilitação em Biologia. Guarantã do Norte: IFMT, 2017

IFMT. Instituto Federal de Educação, Ciência e Tecnologia. Projeto Pedagógico do Curso de Licenciatura em Ciências da Natureza com Habilitação em Biologia. Vila de São Vicente da Serra, Santo Antônio do Leverger: IFMT, 2019a.

IFMT. Plano de desenvolvimento Institucional do IFMT (20192023). Cuiabá: IFMT, 2019b.

KUNZE, N. C. O surgimento da rede federal de educação profissional nos primórdios do regime republicano brasileiro. Rev Bras. Educ. Prof. Tecnol., v.2, n.2, p.8-24, 2009. doi: https://doi. org/10.15628/rbept.2009.2939.

LOPES, A.C.; MACEDO, E. Teorias de Currículo. Rio de Janeiro: Cortez, 2011.

MAGALHÃES-JÚNIOR， C.A.O.M.; PIETROCOLA, M. Análise de propostas para a formação de professores de Ciências do ensino fundamental. Alexandria, v.3, n.2, p.31-58, 2010.
MARQUES, A.A.; INÁCIO FILHO, G.I. Um marco para a história educacional mato-grossense: a criação do aprendizado agrícola Gustavo Dutra. Itinerarius Reflectionis, v.13, n.1, p.119, 2017. doi: https://doi.org/10.5216/rir.v13i1.38926.

MARTINEZ, F.W. Relações de poder, hierarquias e prestígio: Licenciatura em Ciências Biológicas. XIV EDUCERE. Anais... Curitiba: PUC-PR, 2015

NASCIMENTO, T. R. A criação das licenciaturas curtas no Brasil. Rev HISTEDBR, n.45, p.340-346, 2012. doi: https://doi. org/10.20396/rho.v12i45.8640153.

PANSARDI, M.V. Um estranho no ninho: a formação de professores em sociologia nos Institutos Federais. Rev. InterLegere, v.1, n.13, p.235-249, 2013.

PIERSON, A.H.C.; NEVES, M.R. Interdisciplinaridade na formação de professores de Ciências: conhecendo obstáculos. Rev. Bras. Pesq. Educ. Ciênc., v.1, n.2, p.120-131, 2011.

SAMPIERI, R. H.; COLLADO, C.F.; LUCIO, M.P.B. Metodologia de pesquisa. Porto Alegre: Penso, 2013.

SCHNETZLER, R.P. Prática de ensino nas ciências naturais: desafios atuais e contribuições de pesquisa. In: ROSA, D.E.G.; SOUZA, V.C. Didática e práticas de ensino: interfaces com diferentes saberes e lugares formativos. Rio de Janeiro: DP\&A, 2002. p.205-222.

STERING, S.M.S. A educação profissional em Mato Grosso na Era Vargas (1937-1945). Educ. Fronteiras, v.8, n.24, p.46-55, 2018. doi: https://doi.org/10.30612/eduf.v8i24.10254.

TOMITA, N.Y. De história natural a ciências biológicas. Ciênc. Cultura, v.42, n.12, p.1172-1177, 1990.

VIANNA, D.M. Olhando para a formação de professores de Física nos Centros Federais de Educação Tecnológica. In: SIMPÓSIO NACIONAL DE ENSINO DE FÍSICA. Anais...Rio de Janeiro: SBF, 2005. 